\title{
Conversion of Fermented Rice Noodle Wastewater to Microbial Lipid by Mixed Culture of Microalgae and Yeast
}

\author{
Mutiyaporn Puangbut, Suthasinee Rattanachan, Thidarat Papone, and Ratanaporn Leesing
}

\begin{abstract}
Microbial lipids are known as the third generation of biodiesel feedstock. Compared to microbial lipids production, little work has been performed for mixed culture of the oleaginous microalgae and yeasts. In this study, mixed culture of microalgae Chlorella sp. KKU-S2 and yeast Toluraspora maleeae Y30 using fermented rice noodle wastewater hydrolysate (FRNWH) as carbon substrate were investigated under mixotrophic growth for 6 days. Comparison of growth on FRNWH using yeast extract as nitrogen source, $2.71 \mathrm{~g} / \mathrm{L}$ biomass with lipid yield of $117.3 \mathrm{mg} / \mathrm{L}, 2.32 \mathrm{~g} / \mathrm{L}$ biomass with lipid yield of $72 \mathrm{mg} / \mathrm{L}, 2.02 \mathrm{~g} / \mathrm{L}$ biomass with lipid yield of $150.4 \mathrm{mg} / \mathrm{L}$ were obtained from monoculture of $T$. maleeae $\mathrm{Y30}$, Chlorella sp. KKU-S2 and mixed culture of both strains, respectively. Effect of nitrogen source on growth and lipid yield of mixed culture was investigated. Meat extract supported the maximum biomass of $5.32 \mathrm{~g} / \mathrm{L}$ with biomass productivity of $0.89 \mathrm{~g} / \mathrm{L} / \mathrm{d}$ and specific growth rate of $0.28(1 / \mathrm{d})$, while urea supported the maximum lipid yield of $199.0 \mathrm{mg} / \mathrm{L}$ with lipid productivity of $33.17 \mathrm{mg} / \mathrm{L} / \mathrm{d}$. To our knowledge this is the unique report about the microbial lipid production from mixed culture of isolated microalgae and yeast using fermented rice noodle wastewater as carbon substrate under mixotrophic growth.
\end{abstract}

Index Terms-Biodiesel feedstock, microbial lipid, mixed culture, mixotrophic growth.

\section{INTRODUCTION}

Microbial oils, lipid produced from many oleaginous microorganisms involving yeasts, moulds, and microalgae, are known as the third generation of biodiesel feedstock because of their similar fatty acid composition to that of vegetable oils and offer a unique alternative as it does not compete with agricultural food production [1]. Microalgae may assume many types of metabolisms, such as photoautotrophic, heterotrophic and mixotrophic growths [2] Photoautotrophic growth assimilate $\mathrm{CO}_{2}$ and light as carbon and energy sources, respectively, while, heterotrophic growth

Manuscript received May 28, 2015; revised August 2, 2015. This work is financial supported by Khon Kaen University (KKU) Research Fund, fiscal years 2013-2014, The Center for Alternative Energy Research and Development (AERD) and Fermentation Research Center for Value Added Agricultural Products (FerVAAP), Khon Kaen University, Khon Kaen, Thailand.

Mutiyaporn Paungbut and Thidarat Papone are with the Graduate School of Khon Kaen University, Khon Kaen, Thailand (e-mail: mutiyapornp@kkumail.com).

Suthasinee Rattanachan was with the Department of Microbiology, Faculty of Science, Khon Kaen University, Khon Kaen, Thailand (e-mail: sthsn.origins@hotmail.com).

Ratanaporn Leesing is with the Department of Microbiology, Faculty of Science, Alternative Energy Research and Development (AERD) and Fermentation Research Center for Value Added Agricultural Products (FerVAAP), Khon Kaen University, Khon Kaen 40002, Thailand (e-mail: ratlee@kku.ac.th). of microalgae involves the utilization of organic compounds as sole carbon and energy sources under dark condition that could get rid of the dependence on light [3]. Mixotrophic growths of microalgae have an edge over photoautotrophic cultures as they have two energy sources as organic carbon source and light, they can simultaneously drive photoautotrophic and heterotrophic to utilize both inorganic $\left(\mathrm{CO}_{2}\right)$ and organic carbon substrates, they assimilate organic compounds and $\mathrm{CO}_{2}$ as a carbon source, and the $\mathrm{CO}_{2}$ released by microalgae via respiration will be trapped and reused under phototrophic growth [4], [5].

Microalgae Chlorella sp. are widely available strains in the commercial applications as they presented high potentials as biodiesel producers due to their high growth rate, and their high lipid contents [1], [6]. However, the isolated microalgae Chlorella sp. KKU-S2 can grow under photoautotrophic, heterotrophic and mixotrophic conditions and their fatty acid components were palmitic acid, stearic acid, oleic acid and linoleic acid [7].

Oleaginous yeasts are capable of accumulating large amounts of cellular lipids and it also has a high growth rate and can be cultured in a single medium with low cost substrate and some oleaginous yeast strains can accumulate intracellular lipids to level exceeding $70 \%$ of dry biomass [8]. The isolated yeast Torulaspora maleeae Y30 can accumulate high lipid yield and their fatty acids profiles were palmitic acid, stearic acid, and oleic acid that are comparable to vegetable oils [9].

Mixed cultures of microorganisms are common in natural ecological systems. When using a mixed culture, two or more selected species of microorganisms are synchronously cultivated within the same medium, where these microorganisms can mutually exploit complementary metabolic activities to survive, grow, and reproduce [10]. In the mixed culture of yeast and microalgae, under mixotrophic culture, microalgae could act as an oxygen generator from photosynthetic growth for the yeast while the yeast provided $\mathrm{CO}_{2}$ to microalgae and both carried out production of microbial oils [11], [12].

The high cost of microbial-derived biodiesel production is mainly contributed by microbial cultivation and downstream process is essential step as feedstock takes up to $70 \%$ of the overall cost [13], [14]. Glucose is most commonly organic carbon substrate used for sustaining microalgae growing under heterotrophic and mixotrophic cultures of several microalgal species reaching high biomass and lipids productivity [15]-[17], thus the use of this substrate result to high production costs of microbial lipid, then, the cost-effective carbon substrate containing sugar is needed for producing of microbial lipids. Fermented rice noodle wastewater from the typically local factory containing high 
concentration of organic carbon as sugar and starch has been generated during production process and was discharged to receiving water without treatment in many cases [18]. If microalgae could grow in fermented rice noodle wastewater, the organic carbon in wastewater would be reused and the cost of microalgae cultivation would be reduced. Therefore, the aim of this study is to produce microbial lipid from mixed culture of microalgae and yeast by using fermented rice noodle wastewater as carbon substrate and to confirm that mixed culture of both microorganisms could significantly enhance biomass and lipid production.

\section{MATERIALS AND METHODS}

\section{A. Carbon Substrate and Microorganisms}

The carbon substrate used in this study was fermented rice noodles wastewater (FRNW) collected from a local factory in Khon Kaen province, Thailand. The pre-treated FRNW was mixed with sulfuric acid for final concentration of $1 \%(\mathrm{v} / \mathrm{v})$, $\mathrm{pH}$ 3.0-4.0. The mixture was treated in water baht at $100^{\circ} \mathrm{C}$ for $40 \mathrm{~min}$, the liquid fraction as fermented rice noodle wastewater hydrolysate (FRNWH) was separated by centrifugation to remove insoluble particles and neutralized by adding $5 \mathrm{~N} \mathrm{NaOH}$, then stored at $4{ }^{\circ} \mathrm{C}$ prior to use. The reducing sugar of FRNWH was analyzed by DNS method and adjusted the reducing sugar to obtain desirable concentration for used as the carbon substrate.

The microalgae Chlorella sp. KKU-S2 used in this study was isolated from freshwater [7]. Active microalgae cultures for inoculation were obtained in $250 \mathrm{~mL}$ Erlenmeyer flasks with $100 \mathrm{~mL}$ of Bristol's medium supplemented with $20 \mathrm{~g} / \mathrm{L}$ glucose. The seed culture was grown in Bristol's medium supplemented with glucose or FRNWH as carbon substrate at $30^{\circ} \mathrm{C}$ in an incubator rotary shaker at $150 \mathrm{rpm}$ for 3 days under continuous illuminated from overhead by $80 \mathrm{~W}$ cool-white fluorescent lamps. The Bristol's medium contained the following components (mg/L): $\mathrm{NaNO}_{3} 250$, $\mathrm{K}_{2} \mathrm{HPO}_{4} 75, \mathrm{KH}_{2} \mathrm{PO}_{4} 175, \mathrm{CaCl}_{2} 25, \mathrm{NaCl} 25, \mathrm{MgSO}_{4} .7 \mathrm{H}_{2} \mathrm{O}$ 75 , and $\mathrm{FeCl} 20.3, \mathrm{MnSO}_{4} \cdot 2 \mathrm{H}_{2} \mathrm{O} 0.3, \mathrm{ZnSO}_{4} 7 \mathrm{H}_{2} \mathrm{O} 0.2$, $\mathrm{H}_{3} \mathrm{BO}_{3} 0.2, \mathrm{CuSO}_{4} .5 \mathrm{H}_{2} \mathrm{O} 0.06$, and initial $\mathrm{pH}$ was adjusted to 6.0-6.5.

The oleaginous yeast Toluraspora maleeae Y30 used in this study was isolated from forest soil samples [9]. Active yeast cultures for inoculation were obtained in $250 \mathrm{~mL}$ Erlenmeyer flasks with $100 \mathrm{~mL}$ of growth medium containing $20 \mathrm{~g} / \mathrm{L}$ glucose, $20 \mathrm{~g} / \mathrm{L}$ peptone, and $10 \mathrm{~g} / \mathrm{L}$ yeast extract. The seed culture was cultivated in lipid accumulation (LA) medium supplemented with glucose or FRNWH as carbon substrate at $30^{\circ} \mathrm{C}$ in an incubator rotary shaker at $150 \mathrm{rpm}$ for 2 days. The LA medium was consisted of $(\mathrm{g} / \mathrm{L}):\left(\mathrm{NH}_{4}\right)_{2} \mathrm{SO}_{4}$ $0.1, \mathrm{KH}_{2} \mathrm{PO}_{4} 0.4, \mathrm{MgSO}_{4} .7 \mathrm{H}_{2} \mathrm{O} 1.5, \mathrm{ZnSO}_{4} 0.0044, \mathrm{CaCl}_{2}$ $0.0025, \mathrm{MnCl}_{2} 0.0005, \mathrm{CuSO}_{4} 0.0003$ and yeast extract 0.75 and initial $\mathrm{pH}$ was adjusted to 5.0-5.5.

\section{B. Lipid Production}

Batch cultures were performed in $250 \mathrm{~mL}$ Erlenmeyer flasks, each containing $100 \mathrm{~mL}$ of medium supplemented with $15 \mathrm{~g} / \mathrm{L}$ FRNWH (refer to reducing sugar) or glucose, initial inoculums were $3 \%$ yeast and $7 \%$ microalgae (v/v). The flasks were placed in an incubator rotary shaker at 150 $\mathrm{rpm}$ at $30^{\circ} \mathrm{C}$ under continuous illuminated from overhead by
80W cool-white fluorescent lamps for 6 days. The experiments were performed in form of monoculture of each strains and mixed culture of Chlorella sp. KKU-S2 with $T$. maleeae Y30. Lipid production of mixed culture while growth occurs on FRNWH was tested with different types of nitrogen sources. Periodic samples were taken from the flasks to determine the cell biomass and lipid yields, which were then used to calculate the biomass and lipid productivities.

\section{Measurement of Cell Growth, Residual Sugar and Lipid Yields}

The culture broth was centrifuged at 5,000 rpm for $5 \mathrm{~min}$ then the supernatant was analyzed for residual glucose concentration according to DNS method [19]. Harvested biomass was washed twice with distilled water and then dried at $90^{\circ} \mathrm{C}$ to constant weight. The biomass was determined gravimetrically. Cellular lipids were determined by the modified method of Kwon and Rhee [20].

Biomass productivity $(\mathrm{g} / \mathrm{L} / \mathrm{d})$ during the culture period was calculated from the Eq. (1), where $X_{t}$ was the biomass yield $(\mathrm{g} / \mathrm{L})$ at the end of growth phase $\left(t_{t}\right)$ and $X_{0}$ the initial biomass yield $(\mathrm{g} / \mathrm{L})$ at $t_{0}$ (day),

$$
\text { Biomass productivity }=\left(X_{t}-X_{0}\right) /\left(t_{t}-t_{0}\right)
$$

Lipid productivity $(\mathrm{QX}, \mathrm{g} / \mathrm{L} / \mathrm{d})$ at the end of cultivation was calculated from the Eq. (2), where $P_{t}$ was the lipid yield $(\mathrm{g} / \mathrm{L})$ at the end of growth phase $\left(t_{t}\right)$ and $P_{0}$ the initial lipid yield $(\mathrm{g} / \mathrm{L})$ at $t_{0}$ (day),

$$
\text { Lipid productivity }=\left(P_{t}-P_{0}\right) /\left(t_{t}-t_{0}\right)
$$

Process product yield $\left(Y_{P / S}\right)$ at the end of cultivation was calculated from Eq. (3), where $P$ was lipid yield (g/L) and $S$ $(\mathrm{g} / \mathrm{L})$ was consumed carbon substrate,

$$
Y_{P / S}=\text { lipid yield/consumed carbon substrate }
$$

The specific growth rate $(\mu)$ is the slope determined by plotting the natural log of biomass versus time for each substrate concentration during the initial phase of exponential growth before the substrate concentration decreases significantly, while specific rate of lipid production $(q P)$ was a multiple of $\mu$ and $Y_{P / X}$. The specific product yield $\left(Y_{P / X}\right)$ was determined using relationship $\mathrm{d} P / \mathrm{d} X$, while specific cell yield $\left(Y_{X / S}\right)$ was determined using relationship $\mathrm{d} X / \mathrm{d} S$.

\section{Abbreviations}

$P$ : Lipid concentration $(\mathrm{mg} / \mathrm{L}), Q_{P}$ : Volumetric lipid productivity $(\mathrm{mg} / \mathrm{L} / \mathrm{d}), Q_{X}$ : Volumetric biomass productivity (g cells/L/d), $q_{p}$ : Specific rate of lipid production (mg lipid $/ g$ cells/d), $\mu$ : Specific growth rate coefficient $(1 / \mathrm{d})$.

$q_{s}$ : specific rate of substrate consumption (g substrate/g cells/d), $X$ : Biomass concentration $(\mathrm{g} / \mathrm{L}), Y_{P / S}$ : Process product yield (mg lipid/g substrate), $Y_{P / X}$ : Specific product (lipid) yield (mg lipid/g cells), $Y_{X / S}:$ specific ell yield ( $\mathrm{g}$ cells/g substrate).

\section{RESULTS AND DISCUSSION}

\section{A. Effect of Carbon Source on Growth and Lipid Production from Mono- and Mixed Culture}

So far, glucose, cassava starch and Jerusalem artichoke 
hydrolysate have been used as the carbon substrate for lipid production by oleaginous microorganisms [21], [22]. Fermented rice noodle wastewater containing sugar and starch was successfully applied for the cultivation of yeast and mixotrophic growth of microalgae. Thus, affect of carbon source on growth and lipid production of mixed cultures of yeast T. maleeae Y30 and microalgae Chlorella sp. KKU-S2 using yeast extract as nitrogen source were preliminary investigated.

As shown in Fig. 1 and Table I, the biomass and lipid yield of mixed culture grow on glucose was higher than that of mixed culture grow on FRNWH. It was observed that biomass of monoculture of yeast and microalgae were higher than that of mixed culture when cultivated on medium supplemented with FRNWH as carbon substrate. The monoculture of $T$. maleeae Y30 grew faster than that of microalgae Chlorella sp. KKU-S2.

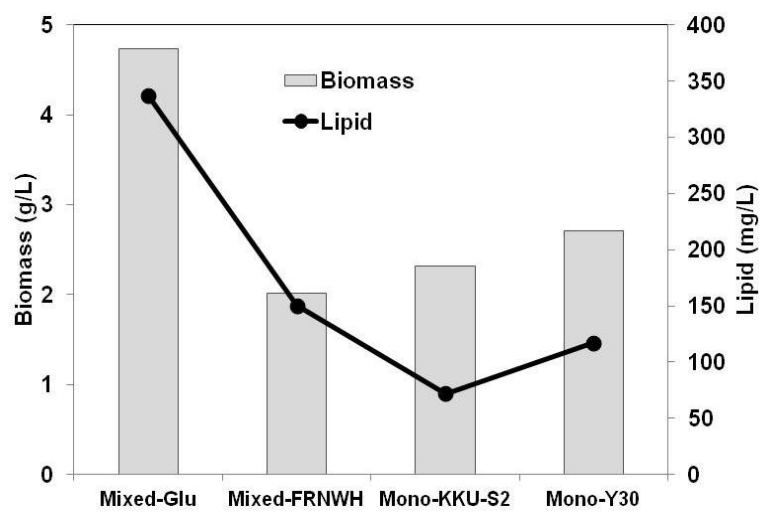

Fig. 1. Biomass and lipid yield during growth of mixed culture and monoculture of T. maleeae Y30 and Chlorella sp. KKU-S2 on culture medium with different culture modes, incubated at $30^{\circ} \mathrm{C}, 150 \mathrm{rpm}$ for 6 days; Mixed-Glu: mixed culture on glucose, Mixed-FRNWH: mixed culture on FRNWH, Mono-KKU-2: monoculture of microalgae-FRNWH, Mono-Y30: monoculture of yeast-FRNWH.

TABLE I: FERMENTATION KinETIC PARAMETERS OF MiXED CULTURE OF CHLORELLA SP. KKU-S2 AND T. MALEEAE Y30 ON CULTURE MEDIUM SUPPLEMENTED WITH GLUCOSE AND FERMENTED RICE NOODLE WASTEWATER HYDROLYSATE AT $30^{\circ} \mathrm{C}$ IN AN INCUBATOR SHAKER AT 150 RPM UNDER CONTINUOUS ILLUMINATION BY USING 80W COOL-WHITE FLUORESCENT LAMPS FOR 6 DAYS

\begin{tabular}{lcccc}
\hline \hline \multirow{2}{*}{$\begin{array}{l}\text { Kinetic } \\
\text { parameters }\end{array}$} & \multicolumn{4}{c}{ Growth condition-carbon substrate } \\
\cline { 2 - 5 } & $\begin{array}{c}\text { culture- } \\
\text { Glucose }\end{array}$ & $\begin{array}{c}\text { Mixed } \\
\text { culture- } \\
\text { FRNWH }\end{array}$ & $\begin{array}{c}\text { Monoculture } \\
\text { KKU-S2- }\end{array}$ & $\begin{array}{c}\text { Monoculture } \\
\text { FRNO-FRNW }\end{array}$ \\
\hline$X$ & 4.73 & 2.02 & 2.32 & H \\
$P$ & 337.0 & 150.4 & 72.0 & 117.3 \\
$Q_{X}$ & 0.79 & 0.34 & 0.39 & 0.45 \\
$Q_{P}$ & 56.17 & 25.06 & 12.01 & 19.54 \\
$Y_{X / S}$ & 0.26 & 0.28 & 0.26 & 0.28 \\
$Y_{P / S}$ & 18.25 & 20.57 & 8.14 & 11.97 \\
$Y_{P / X}$ & 71.34 & 74.60 & 31.11 & 43.26 \\
$\mu$ & 0.26 & 0.12 & 0.14 & 0.17 \\
$q_{P}$ & 18.46 & 8.71 & 4.35 & 7.19 \\
$q_{S}$ & 0.652 & 0.605 & 0.637 & 0.603 \\
\hline \hline
\end{tabular}

$X(\mathrm{~g} / \mathrm{L}) ; P(\mathrm{mg} / \mathrm{L}) ; Q_{X}(\mathrm{~g} / \mathrm{L} / \mathrm{d}) ; Q_{P}(\mathrm{mg} / \mathrm{L} / \mathrm{d}) ; Y_{X / S}(\mathrm{~g}$ cells/g substrate);

$Y_{P / S}\left(\mathrm{mg}\right.$ lipid/g substrate); $Y_{P / X}\left(\mathrm{mg}\right.$ lipid/g cells); $q_{P}(\mathrm{mg}$ lipid /g cells/d); $q_{S}(\mathrm{~g}$ substrate/g cells/ d); $\mu$ (1/d).

It was observed that $\mathrm{pH}$ of medium increased from 5.0 to
7.1 for monoculture of microalgae Chlorella sp. KKU-S2 and from 5.5 up to 7.2 for the mixed culture of Chlorella sp. KKU-S2 with yeast $T$. maleeae Y30, due to the bicarbonate $\left(\mathrm{HCO}_{3}-\right)$ is formed when $\mathrm{CO}_{2}$ dissolves in water at neutral $\mathrm{pH}$. During photosynthesis activity by microalgae, $\mathrm{HCO}_{3}$ - is converted to $\mathrm{CO}_{2}$ and hydroxide ion $(\mathrm{OH})$. Therefore, when $\mathrm{CO}_{2}$ is consumed by microalgae, the hydroxide ion formed, and the $\mathrm{pH}$ becomes more alkaline [17].

In monoculture of yeast T. maleeae Y30, a biomass of $2.71 \mathrm{~g} / \mathrm{L}$ with specific growth rate of $0.17(1 / \mathrm{d})$ and lipid yield of $117.3 \mathrm{mg} / \mathrm{L}$ were obtained. A biomass of $2.32 \mathrm{~g} / \mathrm{L}$ with specific growth rate of $0.14(1 / \mathrm{d})$ and lipid yield of $72 \mathrm{mg} / \mathrm{L}$ were found for monoculture of Chlorella sp. KKU-S2. However, the lipid yield of mixed culture was higher than that of monoculture of yeast and microalgae using both glucose and FRNWH as carbon substrate. The obtained result in this study, FRNWH sounded potential carbon substrate for cell growth and cellular lipid accumulation.

\section{B. Effect of Nitrogen Source on Growth and Lipid Production}

It has been reported that different nitrogen sources had varied influence on microbial lipid production. Therefore, effects of different nitrogen sources on growth and cellular lipid production of mixed culture of Chlorella sp. KKU-S2 and T. maleeae Y30 were tested using $15 \mathrm{~g} / \mathrm{L}$ reducing sugar of FRNWH as carbon substrate.

As shown in Fig. 2 and Table II, among the nitrogen sources tested, meat extract supported the maximum biomass of $5.32 \mathrm{~g} / \mathrm{L}$ with biomass productivity $\left(Q_{X}\right)$ of $0.89 \mathrm{~g} / \mathrm{L} / \mathrm{d}$ while urea supported the maximum lipid yield of $199.0 \mathrm{mg} / \mathrm{L}$ with lipid productivity $\left(Q_{P}\right)$ of $33.17 \mathrm{mg} / \mathrm{L} / \mathrm{d}$. However, Wu et al. (2014) showed that potassium nitrate was the suitable nitrogen source for both cell growth and lipid accumulation of Monoraphidium sp. SB2 under the photoautotrophic conditions [23].

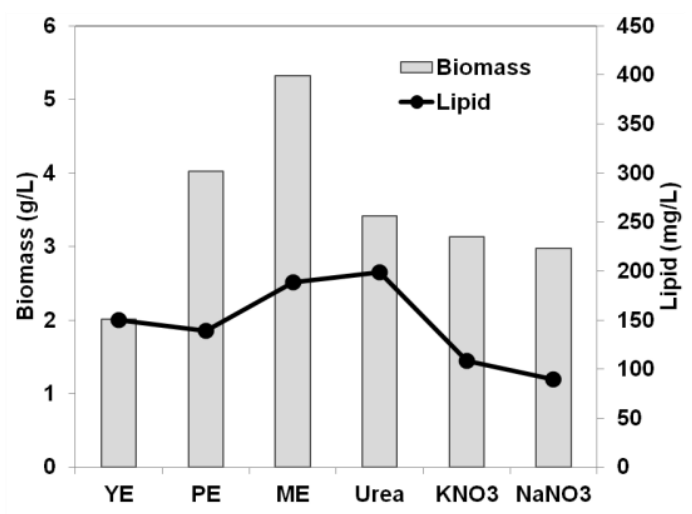

Fig. 2. Biomass and lipid yield of mixed culture of T. maleeae Y30 and Chlorella sp. KKU-S2 on culture medium containing $15 \mathrm{~g} / \mathrm{L}$ reducing sugar of FRNWH with different types of nitrogen sources, incubated at $30^{\circ} \mathrm{C}, 150$ rpm for 6 days under continuous illuminated from overhead by $80 \mathrm{~W}$ cool-white fluorescent lamps; YE: yeast extract; PT: peptone; ME: meat extract.

The promotion effect on growth in mixed cultures can be attributed to sufficient in situ $\mathrm{O}_{2}$ and $\mathrm{CO}_{2}$ transitions, since the microalgae acted as an oxygen generator for the oleaginous yeast, while the oleaginous yeast produces $\mathrm{CO}_{2}$ for the microalgae. As a result, the stresses caused by $\mathrm{CO}_{2}$ on the yeast and $\mathrm{O}_{2}$ on the microalgae were eliminated. Thus, the 
growth conditions were optimized for both species. Additionally, this sufficient in situ transition may maintain an $\mathrm{O}_{2} / \mathrm{CO}_{2}$ balance that enhances the photosynthesis of the microalgae [24].

The result presented that mixed culture of yeast with microalgae could utilized FRNWH as carbon substrate for cell growth and lipid accumulation, suggesting that the costs of microbial lipids production would be reduced and mixed culture technique is a desirable cultivation process for microbial oil production in wastewater.

TABLE II: FERMENTATION KinETIC PARAMETERS OF MiXED CULTURE OF CHLORELLA SP. KKU-S2 AND T. MALEEAE Y30 ON CULTURE MEDIUM CONTAINING 15G/L REDUCING SUGAR OF FERMENTED RICE NOODLE WASTEWATER HYDROLYSATE WITH DIFFERENT NITROGEN SOURCES, AT $30^{\circ} \mathrm{C}$ IN AN INCUBATOR SHAKER AT 150 RPM UNDER CONTINUOUS ILLUMINATION BY USING 80W COOL-WHITE FLUORESCENT LAMPS, 6 DAYS

\begin{tabular}{lcccccc}
\hline \hline \multirow{2}{*}{$\begin{array}{l}\text { Kinetic } \\
\text { parameters }\end{array}$} & \multicolumn{5}{c}{ Nitrogen sources } \\
\cline { 2 - 7 }$X$ & YE & PE & ME & Urea & KNO $_{3}$ & NaNO $_{3}$ \\
\hline$P$ & 2.02 & 4.02 & 5.32 & 3.42 & 3.13 & 2.98 \\
$Q_{X}$ & 150.4 & 139.2 & 188.9 & 199.0 & 108.4 & 89.4 \\
$Q_{P}$ & 0.34 & 0.67 & 0.89 & 0.57 & 0.52 & 0.50 \\
$Y_{X / S}$ & 25.06 & 23.20 & 31.48 & 33.17 & 18.07 & 14.90 \\
$Y_{P / S}$ & 0.28 & 0.56 & 0.58 & 0.54 & 0.85 & 0.55 \\
$Y_{P / X}$ & 20.57 & 19.33 & 20.75 & 31.65 & 29.47 & 16.52 \\
$\mu$ & 74.60 & 34.59 & 35.52 & 58.20 & 34.59 & 30.03 \\
$q_{P}$ & 0.12 & 0.23 & 0.28 & 0.20 & 0.19 & 0.18 \\
$q_{S}$ & 8.71 & 8.03 & 9.89 & 11.93 & 6.58 & 5.46 \\
\hline \hline
\end{tabular}

$X(\mathrm{~g} / \mathrm{L}) ; P(\mathrm{mg} / \mathrm{L}) ; Q_{X}(\mathrm{~g} / \mathrm{L} / \mathrm{d}) ; Q_{P}(\mathrm{mg} / \mathrm{L} / \mathrm{d}) ; Y_{X / S}(\mathrm{~g}$ cells/g substrate); $Y_{P / S}\left(\mathrm{mg}\right.$ lipid/g substrate); $Y_{P / X}\left(\mathrm{mg}\right.$ lipid/g cells); $q_{P}(\mathrm{mg}$ lipid /g cells/d); $q_{S}(\mathrm{~g}$ substrate/g cells/ d)

\section{CONCLUSIONS}

In conclusion, the biomass and lipid yields from mixed culture of Chlorella sp. KKU-S2 and T. maleeae Y30 are notably enhanced in comparison with monoculture. To our knowledge this is the unique report about the production of microbial lipid from mixed culture of yeast and microalgae using FRNWH as carbon substrate. In further works, optimizing of culture condition for increasing of biomass and lipid yield will be investigated by using statistical method such as respond surface methodology and then completed with conversion of microbial biomass to biodiesel fuel by direct transesterification.

\section{REFERENCES}

[1] X. Meng, J. Yang, X. Xu, L. Zhang, Q. Nie, and M. Xian, "Biodiesel production from oleaginous microorganisms," Renewable Energy, vol. 34, pp. 1-5, 2009.

[2] A. L. Ahmad, N. H. Mat Yasin, C. J. C. Derek, and J. K. Lim, "Microalgae as a sustainable energy source for biodiesel production: A review," Renewable and Sustainable Energy Reviews, vol. 15, pp. 584-593, 2011.

[3] X. Miao and Q. Wu, "Biodiesel production from heterotrophic microalgal oil," Bioresour Technol, vol. 97, pp. 841-846, 2006.

[4] L. Brennan and P. Owende, "Biofuels from microalgae-a-review of technologies for production, processing, and extractions of biofuels and co-products," Renew Energ. Rev., vol. 14, pp. 557-577, 2010.

[5] T. Heredia-Arroyo, W. Wei, R. Ruan, and B. Hu, "Mixotrophic cultivation of Chlorella vulgaris and its potential application for the oil accumulation from non-sugar materials," Biomass Bioenergy, vol. 35, pp. 2245-2253, 2011.

[6] Z. Y. Liu, G. C. Wang, and B. C. Zhou, "Effect of iron growth and lipid accumulation in Chlorella vulgaris," Bioresour. Technol., vol. 99, pp. 4717-4722, 2007.

[7] R. Leesing and N. Nontaso, "Microalgal oil production by green microalgae under heterotrophic cultivation," KKU Res J, vol. 9, pp. 787-793, 2010.

[8] O. Tehlivets, K. Scheuringer, and S. D. Kohlwein, "Fatty acid synthesis and elongation in yeast," Biochimica et Biophysica Acta., vol. 1771, pp. 255-270, 2007.

[9] R. Leesing and P. Karraphan, "Kinetic growth of the isolated oleaginous yeast for lipid production," African J. Biotechnol., vol. 10, no. 63, pp. 13867-13877, 2011.

[10] A. M. O'Reilly and J. A. Scott, "Defined coimmobilization of mixed microorganism cultures," Enzyme Microb. Technol., vol. 17, pp. 636-646, 1995.

[11] T. M. Mata, A. A. Martins, and N. S. Caetano, "Microalgae for biodiesel production and other applications: A review," Renew Sust. Energ Rev., vol. 14, pp. 217-232, 2010.

[12] T. I. Pisman and L. A. Somova, "Interaction of a mixed yeast culture in an "autotroph-heterotroph" system with a closed atmosphere cycle and spatially separated components," Adv. Space Res., vol. 3, pp. 1751-1756, 2003.

[13] B. Singh, A. Guldhe, I. Rawat, and F. Bux, "Towards a sustainable approach for development of biodiesel from plant and microalgae," Renew. Sustain. Energy Rev, vol. 29, pp. 216-245, 2014.

[14] D. Pimentel and T. W. Patzek, "Ethanol production using corn, switch grass, and wood; diesel production using soybean and sunflower," Natural Resources Research, vol. 14, pp. 65-76, 2005.

[15] D. Y. Kwon and J. S. Rhee, "A Simple and rapid colorimetric method for determination of free fatty acids for lipase assay," J Am Oil Chem Soc, vol. 63, pp. 89-92, 1986.

[16] G. L. Miller, "Use of dinitrosalicylic acid reagent for determination of reducing sugar," Anal Chem, vol. 31, pp. 426-432, 1959.

[17] A. Richmond, Microalgal Mass Culture, CRC Press, 1986.

[18] S. Siripattanakul, K. Ratanapongleka, P. Sangthean, K. Yoottachana, and K. Pimwongnok, "Fermented rice noodle wastewater treatment and ethanol production potential using entrapped yeast cells," Water Practice Technol., vol. 5, pp. 1-7, 2010.

[19] G. L. Miller, "Use of dinitrosalicylic acid reagent for determination of reducing sugar," Anal Chem., vol. 31, pp. 426-432, 1959.

[20] D. Y. Kwon and J. S. Rhee, "A Simple and rapid colorimetric method for determination of free fatty acids for lipase assay," J. Am Oil Chem Soc, vol. 63, pp. 89-92, 1986.

[21] X. Zhao, S. Wu, C. Hu, Q. Wang, Y Hua, and Z. K. Zhao, "Lipid production from Jerusalem artichoke by Rhodosporidium toruloides Y4," J Ind Microbiol Biotechnol., vol. 37, pp. 581-585, 2010.

[22] M. Li, G. L. Liu, Z. Chi, and Z. M. Chi, "Single cell oil production from hydrolysate of cassava starch by marine-derived yeast Rhodotorula mucilaginosa TJY15a," Biomass Bioenergy, vol. 4, pp. 101-107, 2010.

[23] L. F. Wu et al., "The effects of nitrogen sources and temperature on cell growth and lipid accumulation of microalgae," International Biodeterioration \& Biodegradation, vol. 85, pp. 506-510. 2013.

[24] Q. Dong and X. M. Zhao, "In situ carbon dioxide fixation in the process of natural astaxanthin production by a mixed culture of Haematococcus pluvialis and Phaffia rhodozyma," Catal. Today, vol. 98, pp. 537-544, 2004.

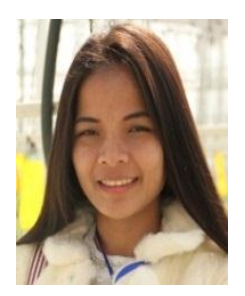

Mutiyaporn Paungbut obtained her bachelor of science degree in biology from Mahasarakham University, Mahasarakham, Thailand. She received her mater degree of science in microbiology from Khon Kaen University, Thailand. She is now a Ph.D. student at the Department of Microbiology, Faculty of Science, Khon Kaen University Thailand. Her research interest for Ph.D. is cultivation of mixed culture of biomass to biodiesel fuel. microalgae and yeast and conversion of microbial

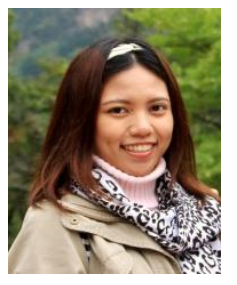

Suthasinee Rattanachan got her bachelor of science degree in microbiology from Khon Kaen University, Khon Kaen, Thailand. Currently she is a master student at the King Mongkut University of Technology, Thonburi, Thailand. 
Thidarat Papone obtained her bachelor degree of science in biology from Mahasarakham University, Mahasarakham, Thailand. Currently she is a Ph.D. student at the Department of Microbiology, Faculty of Science, Khon Kaen University Thailand. Her major $\mathrm{Ph} . \mathrm{D}$. research study areas include microbial oil production from microalgae and oleaginous yeasts and microbial oil-based biodiesel production.

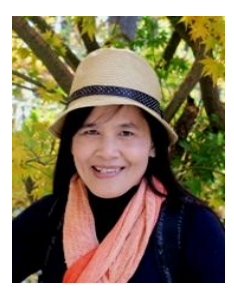

Ratanaporn Leesing is an assistant professor in the Department of Microbiology, Faculty of Science, Khon Kaen University, Khon Kaen, Thailand. She obtained the B.Sc. degree in biology-microbiology from Khon Kaen University, Khon Kaen, Thailand. She received the M.Sc. degree in biotechnology from King Mongkut's University of Technology Thonburi, Bangkok, Thailand and graduated with a Ph.D. degree in food sciences from the University of Montpellier II, Montpellier, France. Her recent research interest and teaching activities are in the field of bio-resources, bio-energy and fermentation technology. 